\title{
Which Way Does Water Flow? \\ An Econometric Analysis of the Global Price Integration of Water \\ Stocks
}

\author{
Eduardo Roca* \\ Department of Accounting, Finance and Economics \\ Griffith Business School \\ Griffith University, Nathan, Queensland, Australia 4111 \\ Tel: 6173735 7583, Fax: 61737353719 \\ Email: E.Roca@griffith.edu.au \\ (corresponding author) \\ Gurudeo Anand Tularam \\ Faculty of Science, Engineering, Environment and Technology \\ Griffith University, Nathan, Queensland, Australia 4111 \\ Tel: 6173735 3522, Fax: 61737356717 \\ Email: A.Tularam@griffith.edu.au
}

\begin{abstract}
Around US\$600 billion of investment is desperately needed to address forecasted huge shortages in water supply globally. A number of worldwide investors - so called water funds, have started to take up this challenge. For these global water investors, knowledge about the extent of integration between the water sectors of financial markets is highly important. According to international portfolio diversification theory, the less (more) integrated markets are, the more (less) benefits there are from international diversification. In this study, we investigate the extent and manner of interdependence among the US, European and Asian water sector of the equity markets based on vector autoregression, Granger causality and impulse response analyses. We find that world water stock market prices are indeed significantly interdependent although this interdependence varies across time periods. Each market quickly responds to shocks from each other and completes its response within three days. Hence, for water investors, international diversification that is undertaken just within the water sector will not be beneficial. The result also implies that there is the risk of cross-market contagion - that is, price volatility spill over across water sectors of different financial markets, and therefore, water authorities in one market should take cognisance of events in other markets.
\end{abstract}

Key Words: Water finance; environmental finance; financial market integration; vector autoregression; variance decomposition; impulse response

Running Title: Global Price Integration of Water Stocks

JEL Classification: Q25, C32, G15

\footnotetext{
* The authors are grateful for the comments and suggestions from the participants in the Department of Finance and Economics Finance Discipline seminar held on May 29, 2009 at Griffith University, particularly Professors Michael Drew and Jerry Bowman.
} 


\title{
Which Way Does Water Flow?
}

\section{An Econometric Analysis of the Global Price Integration of Water}

\author{
Stocks
}

\begin{abstract}
Around US\$600 billion of investment is desperately needed to address forecasted huge shortages in water supply globally. A number of worldwide investors - so called water funds, have started to take up this challenge. For these global water investors, knowledge about the extent of integration between the water sectors of financial markets is highly important. According to international portfolio diversification theory, the less (more) integrated markets are, the more (less) benefits there are from international diversification. In this study, we investigate the extent and manner of interdependence among the US, European and Asian water sector of the equity markets based on vector autoregression, Granger causality and impulse response analyses. We find that world water stock market prices are indeed significantly interdependent although this interdependence varies across time periods. Each market quickly responds to shocks from each other and completes its response within three days. Hence, for water investors, international diversification that is undertaken just within the water sector will not be beneficial. The result also implies that there is the risk of cross-market contagion - that is, price volatility spill over across water sectors of different financial markets, and therefore, water authorities in one market should take cognisance of events in other markets.
\end{abstract}

Key Words: Water finance; environmental finance; financial market integration; vector autoregression; variance decomposition; impulse response

Running Title: Global Price Integration of Water Stocks

JEL Classification: Q25, C32, G15 


\section{Introduction}

Water is a vital commodity. Although $75 \%$ of the earth is covered with water, only $1 \%$ of this water can be used at present. Due to the soaring demand for water arising from population and economic growth, and the negative impact of pollution and climate change water supply, huge water shortages are forecasted in the next ten years. In order to address this problem, there is a need to improve and expand water utilities, water infrastructure, and water treatment plants to increase the quantity of useful water and to improve the delivery of water to users. According to World Bank estimates, these undertakings would require a further investment of around US\$600 billion (Masons Water Yearbook, 2002-2003) to the US\$700 billion a year global water industry (Geman and Kanyinda, 2007).

A number of global institutional investors have started to take up this challenge. Funds dedicated to water investing - so-called water funds, have recently appeared. For example, the North American mutual funds units of Swiss banker Pictet \& Cie have an offering for U.S. investors, the Pictet Global Water Fund. The portfolio is modelled after a similar fund launched in 2000 in Europe. The fund is available in both retail (PGWRX) and institutional (PGWIX) shares. The fund is marketed to retail investors directly from Pictet or through select mutual fund supermarkets with a minimum investment of $\$ 2,500$. Swiss-based SAM Sustainable Asset Management also has a water fund. 
In order to serve the needs of water investors, a number of water indices have also been introduced which serve as the bases for the construction of some water funds. For instance, the American Stock Exchange (AMEX) introduced the Palisades Water Index (ZWI) in December 2003, with a starting value of 1000 points. In August 2005, the AMEX started publishing the ZWI on a regular basis. The Power Shares Water Resources Exchange Traded Fund, directly related to ZWI, was later introduced to investors looking for an exposure to the water industry. In February 2006, Dow Jones and a number of European banks launched the World Water Index (or WOWAX). The French bank, Societe Generale, Dow Jones Indexes, and Sustainable Asset Management - a Swiss management firm that specialises in sustainable development, introduced a certificate replicating the performance of this index in March 2006. The Dutch bank ABN AMRO has a similar product, the ABN Water Certificate. This tradeable certificate is based on the ABN AMRO Water Index which consists of different water companies worldwide - thus, investors are able to obtain diversified exposure to companies involved in water.

For these global investors who are dedicated to the water sector, knowledge about the extent of stock price linkages or integration among world water markets is very important as this determines the profitability of investment diversification across global markets. The theory of international portfolio diversification posits that the less (more) integrated or linked markets are, the more (less) the benefits from international diversification (see, Solnik, 1974 and Solnik and Noetzlin, 1982). The issue of global price integration in the water sector of stock markets, therefore, has important implications for water finance as this will determine which water markets global capital will flow into and in effect, the degree of availability of global capital in 
each national water market. In addition, this knowledge is also highly useful to regulators. If the water sector of stock markets is found to be globally integrated, then there is the risk of international contagion - that is, price volatility in one national market spilling over to another market. Again, this would have very significant implications for investors in water in different countries. This would therefore necessitate coordination in policies across world water markets.

Inspite of its importance to water finance, the issue of price integration in the water sector of world equity markets has not been systematically investigated yet. In the water literature, there are a large number of studies on the economics of water but these studies have been mainly concerned with water pricing and the modelling of cost, supply and demand for water (see, Brewer, et. al, 2007; Monteiro, 2005; Calatrava and Garrido, 2005, among others). There have also been a few studies on the return of investing on water (see, for instance, Geman and Kanyinda, 2007; Buckland and Fraser, 2000) but none of these have focused on the issue of water markets price integration. In the finance literature, there are now a voluminous number of studies which have examined the issue of international integration among equity, bonds and money markets (see, for example, among others, Panopolou, E. and Pantelidis, T., 2009; Chi, et al, 2006; Click and Plummer, 2005; Roca, 1999; Syriopoulos, 2004; Hatemi-J, A. and Roca, E., 2008; Tahai, et al, 2004; Berbena and Jansen, 2009 and Wang, et al, 2003). However, there is no consensus among these studies as to whether markets are integrated or not. Some studies have found that markets are integrated while other studies found the opposite depending on the type of market studied, and the time period and data used. Furthermore, and more importantly, in terms of the motivation of this study, none of these studies on financial 
integration have focused on the water sector of the equity market. Thus, this paper contributes to the water literature, and additionally, to the financial integration literature.

Integration implies equality of price or risk-adjusted returns. It also implies comovements in prices ${ }^{1}$. Investigating integration based on the equality of price or riskadjusted returns requires the use of asset pricing models. This particular approach, however, creates difficulties as the investigation becomes a joint test of integration and the asset pricing model used. For example, if no integration is found, this can mean either that there is indeed no integration at all or that the asset pricing model used is not valid. To avoid this difficulty, this paper looks at integration in terms of co-movement in prices. The extent of integration, based on this approach, may be measured therefore in terms of the degree of the co-movement in prices between markets. The higher the co-movement of prices and the faster the response of prices in one market to the movements of prices in the other market, the greater the degree of integration.

\section{World Water Industry: A Brief Backgrounder}

The global water industry is valued at approximately USD700 billion (Geman and Kanyinda, 2007). The biggest markets can be found in Asia (especially China and Japan), Europe and North America. US-based water companies account for around

\footnotetext{
${ }^{1}$ As argued by Kenen (1976): “... integration refers to the degree to which participants in any market are enabled and obliged to take notice of events occurring in other markets. They are enabled to do so when information about those events is supplied into the decision making processes of recipients. They are obliged to do so when it is supplied in ways that invite them to use it in order to achieve their own objectives...”. This definition therefore, implies information spill-over.
} 
$36 \%$ of the total market capitalisation of the Global Water Sector while European based companies account for around 49\%. The North American market is expected to only experience modest growth rates in the coming years heavily influenced by public budgets and water-related policies. The European market will also experience sluggish growth rates. On the other hand, the Asian market, particularly China and Japan, is expected register growth rates of over $10 \%$ in the years to come. The investment performance of the US water industry has been lower than the European and Asian-based water sectors in recent years (MFS Water Fund brochure, April 2, 2007).

The water industry is fragmented in the sense that it involves very many and diverse water plants. Globally, there are about 250,000 water plants operating under very different economic and legal conditions. However, a number of global water companies have managed to undertake consolidation of plants through acquisitions of small plants. These global players have also worked on developing global distribution networks. Globally active private operators now account for $19 \%$ of investments in facilities for drinking water supply and waste water treatment. This proportion is expected to rise to 30\% by 2016 (Global Water Intelligence, 2007). As mentioned earlier, there are now funds that are investing in the water industry worldwide. These investors are therefore making the financial markets for the water industry globalised. Thus, even if water is not traded globally, with this globalisation of investment, it is expected that the water sector of the stock markets will be integrated -that is, they will have very significant price interactions. The objective of this paper is to examine the structure, in terms of extent, speed and duration, of these price interactions between the water sectors of stock markets globally. 


\section{Methodology and Data}

\subsection{Methodology}

The study examines the structure of dynamic linkages among the three water markets within the context of a vector autoregression (VAR) analysis (Sims, 1980). As previously stated, in particular, the study investigates the extent, speed and duration of interaction among the three markets - the US, Europe, and Asia, based on Granger causality, impulse response and variance decomposition analyses.

Vector Autoregression

We estimate a three market VAR system shown as follows:

$$
y_{t}=\alpha+\sum_{k=1}^{L} \beta_{k} y_{t-k}+\varepsilon_{t}
$$

where $y_{t}$ is a $\mathrm{n} \times 1$ column vector of weekly market returns, $\alpha$ and $\beta_{t}$ are respectively, $3 \times 1$ and $3 \times 3$ matrices of coefficients, $L$ is the lag length and $\varepsilon_{t}$ is a $3 \times 1$ column vector of serially uncorrelated error terms, The $i, j^{\text {th }}$ component of $\beta_{k}$ measure the direct effect on the $i^{\text {th }}$ market of a change in the return to the $j^{\text {th }}$ market in the $k$ periods. In effect, the $i$ th component of $\varepsilon_{t}$ is the innovation of the $i^{\text {th }}$ market which cannot be predicted from past returns of other markets in the system. 
More generally, the return data in Equation (1) can be written as $y_{t}=\left(y_{1}, y_{2 t}, y_{3 t}\right)^{\mathrm{T}}$ denoting vector containing the observations of the $3(n)$ variables at time $t$. Hence, the multivariate data is represented by a VAR process of order $p, \operatorname{VAR}(p)$ in Equation 2 (Bruggemann et al., 2008);

$$
y_{t}=\Phi_{0}+\Phi_{1} y_{t-1}+\ldots+\Phi_{p} y_{t-p}+\varepsilon_{t}
$$

where $\Phi_{0}$ is a $n \times 1$ vector of intercept parameters, $\Phi_{i}, i=1,2, \ldots, p$, are fixed $n \times n$ parameter matrices and, $\varepsilon_{t}=\left(\varepsilon_{1 t}, \ldots, \varepsilon_{n t}\right)$, is an unobservable error term vector with mean zero and time-invariant, non-singular covariance matrix $u$, i.e., $E\left[\varepsilon_{t}, \varepsilon_{t}^{T}\right]=\Sigma_{\varepsilon}$.

\section{Granger Causality Analysis}

The Granger causality analysis (Granger, 1969) enables the study to examine which market is influencing which and therefore to identify which market is the leader and which ones are the followers. Stated in simple mathematical terms, the Granger causality test is of the following kind: $x$ does not granger-cause $y$ if and only if, prediction of $y$ based on the universe $U$ of predictors is no better than the prediction of $y$ based on $U-\{x\}$; that is, the universe with $x$ omitted.

More generally, where $\mathbf{y}_{\mathrm{t}}=\left(\mathrm{y}_{1 \mathrm{t}}, \ldots, \mathrm{y}_{\mathrm{nt}}\right)$ representing $\boldsymbol{n}$ variables: “ $\mathrm{y}_{2 \mathrm{t}}$ granger-causes $\mathrm{y}_{1 \mathrm{t}}$ if past values of $\mathrm{y}_{2 \mathrm{t}}$ help in predicting $\mathrm{y}_{1 \mathrm{t}}$ in the presence of past values of $\mathrm{y}_{1 \mathrm{t}}$. ”. That is, given:

$$
\mathrm{y}_{1 \mathrm{t}}=\mathrm{c}_{1}+\alpha_{1} \mathrm{y}_{1 \mathrm{t}-1}+\ldots+\alpha_{\mathrm{p}} \mathrm{y}_{1 \mathrm{t}-\mathrm{p}}+\beta_{1 \mathrm{y}_{2 \mathrm{t}-1}}+\ldots+\beta_{\mathrm{p}} \mathrm{y}_{2 \mathrm{t}-\mathrm{p}}+\varepsilon_{1 \mathrm{t}}
$$


test the following: $\mathrm{H}_{0}: \beta_{1}=\ldots=\beta_{\mathrm{p}}=0$ (no causality from $\mathrm{y}_{2 \mathrm{t}}$ to $\mathrm{y}_{1 \mathrm{t}}$ ) using an F-test. If the null is not rejected, then $\mathrm{y}_{2 \mathrm{t}}$ does not granger-cause $\mathrm{y}_{1 \mathrm{t}}$. In a similar manner, to see if $\mathrm{y}_{1 \mathrm{t}}$ granger-causes $\mathrm{y}_{2 t}$, use:

$$
\mathrm{y}_{2 \mathrm{t}}=\mathrm{c}_{1}+\alpha_{1} \mathrm{y}_{1 \mathrm{t}-1}+\ldots+\alpha_{\mathrm{p}} \mathrm{y}_{1 \mathrm{t}-\mathrm{p}}+\beta_{1} \mathrm{y}_{2 \mathrm{t}-1}+\ldots+\beta_{\mathrm{p}} \mathrm{y}_{2 \mathrm{t}-\mathrm{p}}+\varepsilon_{1 \mathrm{t}}
$$

and test $\mathrm{H}_{0}: \alpha_{1}=\ldots=\alpha_{\mathrm{p}}=0$ (no causality from $\mathrm{y}_{1 \mathrm{t}}$ to $\mathrm{y}_{2 \mathrm{t}}$ ). If the null is not rejected, then $\mathrm{y}_{1 \mathrm{t}}$ does not granger-cause $\mathrm{y}_{2 \mathrm{t}}$.

For a simpler example, in a 2 variable analysis one can partition $\mathrm{y}_{\mathrm{t}}$ into two subvectors and then use the definition by Granger (1969) in terms of forecast performance. In this sense $\mathrm{y}_{1 \mathrm{t}}$, does not granger cause $\mathrm{y}_{2 \mathrm{t}}$ if it does not help in predicting $\mathrm{y}_{2 \mathrm{t}}$. If we let $\mathrm{y}_{\mathrm{t}}$ be a stationary process and define the linear subspaces: $\mathrm{M}_{t}^{1}=s p\left\{y_{1 s}, s \leq t\right\}$ and $\mathrm{M}_{t}^{2}=s p\left\{y_{2 s}, s \leq t\right\} \quad, \quad$ then $\quad \mathrm{y}_{1 \mathrm{t}} \quad$ causes $\quad \mathrm{y}_{2 \mathrm{t}} \quad$ if $P_{\left[\mathrm{M}_{t-1}^{2} \cup \mathrm{M}_{t-1}^{2}\right]}\left(\mathrm{y}_{2 \mathrm{t}}\right) \neq P_{\left[\mathrm{M}_{t-1}^{2}\right]}\left(\mathrm{y}_{2 \mathrm{t}}\right) \quad$ and $\quad \mathrm{y}_{1 \mathrm{t}} \quad$ causes $\quad \mathrm{y}_{2 \mathrm{t}} \quad$ instantaneously if $P_{\left[\mathrm{M}_{t}^{2} \cup \mathrm{M}_{t-1}^{2}\right]}\left(\mathrm{y}_{2 \mathrm{t}}\right) \neq P_{\left[\mathrm{M}_{t-1}^{2}\right]}\left(\mathrm{y}_{2 \mathrm{t}}\right)$ where $\mathrm{P}$ is projection. It follows at once from the definition of Granger causality and the projection theorem that $\mathrm{y}_{1 \mathrm{t}}$ does not grangercause $\mathrm{y}_{2 \mathrm{t}}$ if $\operatorname{var}\left(\varepsilon_{t}^{1}\right)=\operatorname{var}\left(\varepsilon_{t}^{1}\right)$ where

$$
\varepsilon_{t}^{1}=y_{2 t}-P_{\left[\mathrm{M}_{t-1}^{2} \cup \mathrm{M}_{t-1}^{2}\right]}\left(\mathrm{y}_{2 \mathrm{t}}\right) \text { and } \varepsilon_{t}^{1}=y_{2 t}-P_{\left[\mathrm{M}_{t-1}^{2}\right]}\left(\mathrm{y}_{2 \mathrm{t}}\right) \text {. }
$$

More particularly, in $\mathrm{n}=2$ case scenario the VAR may be written as Equation 6:

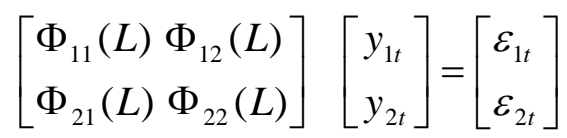


where $\varepsilon_{1 t}$ and $\varepsilon_{2 s}$ are uncorrelated for all $s$ and $t$. Then $y_{1 t}$ does not granger cause $y_{2 t}$ if $\Phi_{21}(L)=0$ as evident the above VAR. If $\phi^{-1}(L)$ exist then $\mathrm{MA}(\infty)$ of the above system can be written a shown in Equation 7.

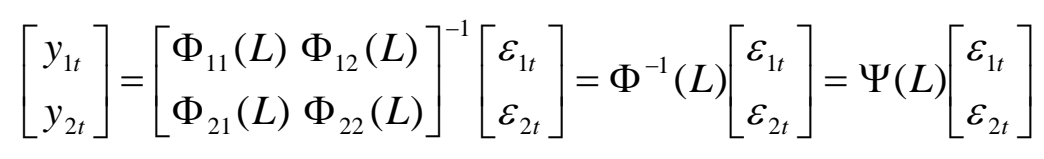

Therefore, $\Phi(L) \Psi(L)=I$ and more particularly, given I is the identity, $\Phi_{21}(L) \Psi_{11}(L)+\Phi_{22}(L) \Psi_{21}(L)=0$. Furthermore, this suggests $\Psi_{21}(L)=0$ if and only if $\Phi_{22}(L) \neq 0$ given that $\Phi_{21}(L)=0$ given earlier. All of this means Equation 8:

$$
\left[\begin{array}{l}
y_{1 t} \\
y_{2 t}
\end{array}\right]=\left[\begin{array}{cc}
\Psi_{11}(L) & \Psi_{12}(L) \\
0 & \Psi_{22}(L)
\end{array}\right]\left[\begin{array}{l}
\varepsilon_{1 t} \\
\varepsilon_{2 t}
\end{array}\right]
$$

If $\mathrm{y}_{1 \mathrm{t}}$ fails to granger cause $\mathrm{y}_{2 t}$. This leads to the following:

$y_{1 t}=\Psi_{11}(L) \varepsilon_{1 t}+\Psi_{12}(L) \varepsilon_{2 t} \quad$ and $\quad \Phi_{22}(L) y_{2 t}=\varepsilon_{2 t} \quad$ from $\quad$ earlier, $\quad$ suggesting $y_{1 t}=\Psi_{11}(L) \varepsilon_{1 t}+\Psi_{12}(L) \Phi_{22}(L) y_{2 t} \quad ; \quad$ and based on projection theorem, $P_{M_{t}^{2}}\left(y_{1 t}\right)=\Psi_{12}(L) \Phi_{22}(L) y_{2 t}$. The first error term is orthogonal to $M_{t}^{2}$ whence it follows that $\operatorname{cov}\left(y_{2 t+j}, y_{1 t}-\Psi_{12}(L) \Phi_{22}(L) y_{2 t}\right)=\operatorname{cov}\left(y_{2 t+j}, \Phi_{11}(L) \varepsilon_{1 t}\right)=0, \forall j>0$. That is, a covariance of zero is an alternative suggesting no granger causality exists.

Impulse Response Analysis 
We determine the speed and duration of interaction among the markets through an impulse response analysis. If the responses subside towards zero quickly then the transmissions between these markets are relatively efficient. The impulse response analysis is conducted based on the generalised approach developed by Pesaran and Shin (1998). This method avoids variations in results arising out of the ordering of variables - a problem that arises when the Cholesky decomposition approach (see Eun and Shim, 1989) is utilised.

The impulse response functions trace the effects of a shock to one endogenous variable on to the other variables in the VAR. The dynamic relationships between variables are captured by the impulse response function. If the $\operatorname{VAR}(p)$ model is stationary it has a moving average (MA) representation as shown in Equation 9:

$$
y=\mu+\sum_{i=0}^{\infty} \Gamma_{i} \varepsilon_{t-i}
$$

where $\mu=\left(I_{n}-\Phi_{1}-\cdots-\Phi_{p}\right)^{-1} \Phi_{0}$ is the mean of the process. The MA matrices, $\Gamma_{i}$ contain the responses to forecast errors $\varepsilon_{t}$ that occurred $i$ periods ago. These responses are difficult to interpret if the contemporaneous residual correlation is high.

As noted earlier, a Cholesky decomposition has been used to orthogonalize the shocks as obtained by a of $\Sigma_{\varepsilon}$ but the impulse response analysis may depend on the ordering of the variables. Therefore, to remove such dependence the authors use the generalized impulse responses introduced by Pesaran and Shin (1998). The shocks are orthogonalized by looking at a shock in variable $n$; and then integrating out the effects of other shocks using the distribution of the errors. In this manner, the 
correlation among the components of $\varepsilon_{t}$ is taken into account. If $\varepsilon_{t}$ has a multivariate normal distribution, then according to Bruggemann et al. (2008) it can be shown that

$$
E\left[\varepsilon_{t} \mid \varepsilon_{n t}=\delta_{n}\right]=\left(\sigma_{1 n}, \sigma_{2 n} \ldots, \sigma_{N n}\right)^{T} \sigma_{n n}{ }^{-1} \delta_{n}=\Sigma_{\varepsilon} e_{n} \sigma_{n n}{ }^{-1} \delta_{n}
$$

where $\left\{\sigma_{n j}, j, n=1, \ldots, N(=3)\right\}$ denotes the elements of $\Sigma_{\varepsilon}$ and $e_{n}$ is a $n \times 1$ selection vector with a 1 in position $n$ and zeros elsewhere. Hence, the response vector to a shock in variable $n$ that occurred $i$ periods ago is as shown Equation 11:

$$
\frac{\Gamma_{i} \Sigma_{\varepsilon} e_{n} \delta_{n}}{\sigma_{n n}}=\frac{\Gamma_{i} \Sigma_{\varepsilon} e_{n}}{\sqrt{\sigma_{n n}}} \frac{\delta_{n}}{\sqrt{\sigma_{n n}}}
$$

A scale may be used here for $\delta_{n}$ so that the shocks have a size of one standard deviation, i.e., we set $\delta_{n}=\sqrt{\sigma_{n n}}$. In such a manner, the analysis can help obtain response vectors; namely, (as shown in Equation 12):

$$
\theta_{n}(i)=\frac{\Gamma_{i} \Sigma_{\varepsilon} e_{n}}{\sqrt{\sigma_{n n}}} \text { for } i=0, . ., h
$$

that gives the generalized impulse responses of the variables in $y_{t}$ to a shock in variable $n$ that occurred $i$ periods ago.

\section{Variance Decomposition Analysis}

In order to determine the extent by which one market affects another market, we perform a variance decomposition analysis within the context of a vector autoregression. The variance decomposition decomposes variation in an endogenous variable into the component shocks to the endogenous variables in the VAR. The generalized impulse analysis aids the derivation of error variance decompositions. 
Variance decomposition is the proportion of the h-step forecast error variance of variable $i$ that is accounted by the innovations of variable $j$ in the defined VAR (Pesaran and Shin, 1998).

Denoting the $i j^{\text {th }}$ element of the orthogonalized impulse response coefficient matrix, $\Psi_{n}$ by $\psi_{i j, n}$ the variance of forecast error is given as $y_{k T+h}-\left\{y_{k T+h}\right.$ given $\left.T\right\}$ is given in Equation 13.

$$
\sigma_{k}^{2}(h)=\sum_{n=0}^{h-1}\left(\psi_{k 1, n}^{2}+\psi_{k 2, n}^{2}+\ldots+\psi_{k K, n}^{2}\right)=\sum_{j=0}^{K}\left(\psi_{k j, 0}^{2}+\psi_{k j, 1}^{2}+\ldots+\psi_{k j, h-1}^{2}\right)
$$

The second form is interpreted as contributions of variable $j$ to the $h$ step forecast error variance of variable $k$. Dividing the above terms by $\sigma_{k}^{2}(h)$ provides the percentage contribution of variable $j$ to the h- step forecast error variance of variable $k$ (Lutkepohl, 1991).

$$
\omega_{k j}(h)=\frac{\psi_{k j, 0}^{2}+\psi_{k j, 1}^{2}+\ldots+\psi_{k j, h-1}^{2}}{\sigma_{k}^{2}(h)}
$$

However, based on the generalized forecast error variance (Pesaran and Shin, 1998), the form used in this study is shown Equation 15 (for notation details see earlier notes including Equations 9 and 11):

$$
\theta_{i j}^{g}(n)=\frac{\sigma_{i i}^{-1} \sum_{l=0}^{n}\left[e_{i}^{\prime} \Gamma_{l} \Sigma_{\varepsilon} e_{j}\right]^{2}}{\sum_{l=0}^{n} e_{i}^{\prime} \Gamma_{l} \Sigma_{i} \Gamma_{l} e_{l} e_{j}} \text { for } i, j=1, \ldots, m
$$


We conduct a number of diagnostic tests are conducted before performing the VAR analysis. In order to determine the stationarity of the data, unit root tests based on the Augmented Dickey Fuller and Phillips Peron tests are performed first. The optimal lags to be used in the model are also tested first based on the Schwartz Information (SIC) criterion. As these tests are already well-known in the literature, discussions of these tests are no longer provided.

\subsection{Data}

The study utilises the DS Water Index for the US, Europe and Asia which are obtained from the Thomson Datastream database. The index consists of companies which represent $75 \%$ to $80 \%$ of the market capitalisation. The sample period is from July 1, 1993 to October 31, 2007. We allow for structural break arising from the September 11, 2001 crisis, so we divide the sample period into two sub-periods, as follows: (1) pre-crisis period from July 1, 1993 to September 10, 2001; and (2) postcrisis period from September 17, 2001 to October 31, 2007. Daily data is utilised in the form of returns on the price indexes calculated by the following formula: $R_{t}=$ $\ln \left(\right.$ price $_{t} /$ price $\left._{t-1}\right) \times 100^{2}$. All returns are expressed in US dollars.

\section{Empirical Results}

\section{Data Preliminaries}

\footnotetext{
2 The continuous return formula is used as it is well-known to provide more accurate measure of return compared to the discrete formula (Brailsford et al, 2004, pp. 9).
} 
All indices have increased over the entire period. The US performance exhibits the best performance - very much above the European and Asian markets. The performance of the European and Asian markets are quite similar.

\section{[Insert Figure 1 Here]}

As can be seen in Table 1, there are non-normalities in the data; however, each data series is stationary as indicated by the results of the ADF and PP tests.

\section{[Insert Table 1 Here]}

Table 2 shows the correlation coefficients between the different markets. During the period before September 11 (period 1), the US and Europe as well as Europe and Asia are significantly correlated; however, the US and Asia are not. After September 11 (period 2), all markets are significantly correlated. Thus, it appears that the markets became more interlinked after the September 11 crisis.

\section{[Insert Table 2 Here]}

These results, however, should be taken with caution as it is highly known that correlations are static and based on the assumption of linearity. We therefore undertake a further analysis of the markets' relationships based on Granger causality, variance decomposition and impulse response analyses within a Vector Autoregression (VAR) framework. We first determine the optimal lag of the VAR. Based on the results of the Shwartz Information Criterion test which are shown in Table 3, the optimal lag is 1 . 
[Insert Table 3 Here]

\title{
Granger Causality Test Results
}

The estimates of the VAR coefficients are presented in Table 4. It can be seen from this table that all coefficients are significant which means that all markets are significantly linked. Since all variables are non-stationary and therefore not cointegrated, we conduct the Granger causality test based on Equation 8. The results of the Granger causality test which are presented in Table 5 indicate that there is a twoway Granger-causality between any pair of markets. Each market therefore affects each other. During the post-crash period, the effect of Asia on Europe and the US slightly weakened in the post-crash period (as shown by the slightly lower level of significance in the latter period) while the impact of Europe and the US on Asia slightly strengthened. The flow and strength of causality or interaction between the markets is summarised in Figure 2.

\author{
[Insert Table 4 Here] \\ [Insert Table 5 Here] \\ [Insert Figure 2 Here]
}

\section{Variance Decomposition Analysis Results}

Table 6 presents the results of the variance decomposition (VDC) analysis. The numbers in each row show the percentage of the forecast variance for a particular market (listed in each row) accounted for by shocks coming from each market listed in each column. The value in the diagonal line is the percentage of each market's 
forecast variance that is due to itself. The values in the last column refer to the total percentage of a market's (listed in each row) forecast variance due to all other markets. Each value shown in the row "total effect on other markets" is the percentage of the forecast variance of all other markets that due to a particular market (listed in each row).

It can be seen from the table that the values in the diagonal lines have decreased while the values shown in the last column have increased during the period after the crisis (period 2). In fact, the overall total effect from other markets increased from $0.94 \%$ in period 1 to $6.24 \%$ in period 2. This means that the markets have become less affected by their own shocks and more affected by external shocks. This provides further evidence that the markets have become more interdependent and therefore integrated. Of the three markets, it can also be seen from Table 6 that the US has the lowest values in the diagonal lines and highest values in the last column, in both periods. This indicates that the US is the most open of the three markets. Europe is the most influential market as it accounted for the largest percentage of forecast variance of other markets in both periods. As can be seen in the row "total effect on other markets”, in period, Europe accounted for $0.53 \%$ of the forecast variance of the other two markets, Asia $0.37 \%$ and US $0.04 \%$. In period 2, Europe sill for the biggest portion of the forecast variance of other markets with a huge increase to $4.36 \%$, followed by the US at $1.10 \%$ and then Asia at $0.78 \%$.

Thus, in summary, the VDC analysis reveals that the markets have become interdependent with each other after the crisis. The US is the most open of all markets while Europe is the most influential. 


\section{[Insert Table 6 Here]}

\section{Impulse Response Analysis Results}

We determine the speed and duration of interaction among the markets through an impulse response analysis. The impulse response functions trace the effects of a shock to one endogenous variable on to the other variables in the VAR. The dynamic relationships between variables are captured by the impulse response function. If the responses subside towards zero quickly then the transmissions between these markets are relatively efficient. The impulse response analysis is conducted based on the generalised approach developed by Pesaran and Shin (1998). This method avoids variations in results arising out of the ordering of variables - a problem that arises when the Cholesky decomposition approach (see Eun and Shim, 1989) is utilised.

[Insert Figure 3 Here]

\section{Conclusion}

This paper investigates the extent and manner of interdependence among the US, European and Asian water sector of the equity market based on Granger causality, variance decomposition and impulse response analyses in the context of vector autoregression. The results show that the three water markets are significantly linked and therefore may be considered as significantly integrated. There is two-way causality between any pair of markets. The variance decomposition analysis reveals that the markets became more interdependent with each other during the postSeptember 11 period with the US becoming most open and Europe being the most 
influential. The results of the impulse response analysis overwhelmingly reveal that each market efficiently responds to shocks coming from another market with the response being completed within three days.

For stock market investors dedicated to the water sector, these results imply that diversifying worldwide will not yield additional benefits. Thus, in order to achieve beneficial diversification, it would be necessary for investments in the water sector to be done within a portfolio of investments in other sectors or assets. This could be a topic for future research - in terms of identifying the optimal composition of this portfolio. This implies therefore that the water industry would have to compete with other sectors for a share of the flow of global capital.

The findings also imply that there is the risk of international contagion or spill-over between the water sectors of stock markets and therefore regulators within one water market should take cognisance of developments in other markets. Despite water not being an internationally traded commodity, investors in this sector are global. Thus, the actions of investors in one market affect the price of water shares in other markets. Again, this has very significant implications on the availability and flow of capital into the water sector of different countries. For example, a significant development in the water industry in another country may lead to an outflow of capital from the water industry in a certain country. In order to further understand this issue, there is therefore a need for research on the factors that drive the relationship between water sectors of stock markets worldwide. 


\section{References}

Berbena, R. and Jansen, W. (2009). "Bond Market and Stock Market Integration in Europe: A Smooth Transition Approach”, Applied Economics, 41, 24, 30673080.

Brailsford, T., Heaney, R. and Bilson, C. (2004) "Investments: Concepts and Applications", 2nd ed, Thomson, South Melbourne.

Brewer, J.; Glennon, R.; Ker, A.; Libecap, G. (2007). "Water Markets in the West: Prices, Trading, and Contractual Forms”, Discussion Paper No. 07-07, Arizona Legal Studies, downloaded from the Social Science Research Network website (http://ssrn.com/abstract=964819).

Bruggemann, R., Hardle, W., Mungo, J., and Trenkler, C. (2008). "VAR Modelling For Dynamic Loadings Driving Volatility Strings”. Journal of Financial Econometrics, 2008, 1-21.

Buckland, R. and Fraser, P. (2000). “Abnormal Returns in the UK Water Industry since Privatisation”, Working Paper 00-10, Aberdeen Papers in Accountancy, Finance and Management, University of Aberdeen, Scotland.

Calatrava, J. and Garrido, A. (2005). “Modelling Water Markets Under Uncertain Water Supply”, European Review of Agricultural Economics, 32(2), 119-142.

Chi, J.; Le, K.; and Young, M. (2006). “Financial Integration in East Asian Equity Markets”, Pacific Economic Review, 11(4), 513-526.

Click, R.W. and Plummer, M.G. (2005). "Stock Market Integration in ASEAN after the Asian Financial Crisis”, Journal of Asian Economics, 16, 5-28.

Engle, R. F. and C. W. J. Granger (1987) “Cointegration and Error Correction: Representation, Estimation, and Testing,” Econometrica, 55 (2), 251-76.

Eun, C. S. and S. Shim, (1989) "International Transmission of Stock Market Movements”, Journal of Financial and Quantitative Analysis, 24, 241-256.

Geman, H. and A. Kanyinda (2007). "Water as the Next Commodity”, The Journal of Alternative Investments, 20, 2, 23-31.

Global Water Intelligence, (2007). Global Water Market 2008.

Granger, C. W. J. (1969) “Investigating Causal Relationships by Econometric Models and Cross spectral Models”, Econometrica, 37, 424-38. 
Hatemi-J, A. and Roca, E. (2008). “Equity Market Price Interdependence: Evidence from Australia and Its Major Trading Partners Based on Bootstrap Causality Tests”, Applied Financial Economics, 2008, 17, 10, 827-835.

Kenen, P.B. (1976) "Capital Mobility and Financial Integration: A Survey”, Princeton Studies in International Finance, No. 39, Princeton University.

Lin, A. and P.E. Swanson (1993). Measuring Global Money Market Interrelationships: An Investigation of Five Major World Currencies, Journal of Banking and Finance, 17, 609-628.

Lutkepohl, H. (1991). Introduction to Multiple Time Series Analysis. Berlin: Springer-Verlag.

Monterio, H. (2005). "Water Pricing Models: A Survey”, Working Paper No. 2005/45, Centro de Estudos Sobre a Mudanca Socioeconomica, Lisboa, Portugal.

Panopolou, E. and Pantelidis, T. (2009). “Integration at a Cost: Evidence from Volatility Impulse Response Functions”, Applied Financial Economics, 19, 917933.

Perman, R. (1991). “ Cointegration: An Introduction to the Literature”, Journal of Economic Studies, 18, 3, 3-30.

Pesaran, M.H. and Y. Shin, (1998) "Generalized impulse response analysis in linear multivariate models”, Economics Letters, 58, 17-29

Roca, E.D., (1999) "Short-term and Long-term Price Linkages between the Equity Markets of Australia and its Major Trading Partners”, Applied Financial Economics, 9, 501-511

Sims, C.A., (1980) “Macroeconomics and Reality”, Econometrica, 48, 1-48

Solnik, B. (1974). “Why Not Diversify Internationally?”, Financial Analysts Journal, 20, 4, (July/Aug), 48-54.

Solnik, B. and Noetzlin, B. (1982). “Optimal International Asset Allocation”, Journal of Portfolio Management, 2 (Fall), 11-21.

Syriopoulos, T. (2004), International Portfolio Diversification to Central European Stock Markets, Applied Financial Economics, 14, 17, 1253-1268.

Tahai, A.; Rutledge, R. and Karim, K. (2004). “An Examination of Financial 
Integration for the Group of Seven (G7) Industrialised Countries Using an I( ) Cointegration Model, Applied Financial Economics, 14, 4, 327-335.

United Nations (2005). Population Challenges and Development Goals.

Wang, Z.; Yang, J. and Bessler, D.A. (2003). “Financial Crisis and African Stock Market Integration”, Applied Economics Letters, 10, 9, 527-534. 
Table 1

Descriptive Statistics

\begin{tabular}{|c|c|c|c|}
\hline & ASIA & EUROPE & US \\
\hline \multicolumn{4}{|c|}{ Period 1 (01/07/1993-10/09/2001) } \\
\hline Mean & -0.045 & -0.018 & -0.043 \\
\hline Median & 0.005 & 0.000 & 0.000 \\
\hline Maximum & 39.498 & 9.995 & 7.715 \\
\hline Minimum & -35.406 & -8.379 & -8.764 \\
\hline Std. Dev. & 3.428 & 1.180 & 1.457 \\
\hline Skewness & -0.723 & -0.129 & -0.230 \\
\hline Kurtosis & 23.261 & 8.327 & 5.835 \\
\hline Jarque-Bera & $36,754.490(0.000)^{*}$ & $2,534.162(0.000)^{*}$ & $734.980(0.000)^{*}$ \\
\hline $\mathrm{ADF}$ & - $47.903(0.000)^{* * *}$ & $-40.474(0.00)^{* * *}$ & $-47.737(0.00)^{* * *}$ \\
\hline $\mathrm{PP}$ & $-47.895(0.00)^{* * *}$ & $-40.439(0.00)^{* * *}$ & $-47.737(0.00)^{* * *}$ \\
\hline \multicolumn{4}{|c|}{ Period 2 (17/09/2001-31/10/2007) } \\
\hline Mean & -0.103 & -0.062 & -0.073 \\
\hline Median & - & -0.055 & -0.012 \\
\hline Maximum & 6.637 & 4.853 & 7.394 \\
\hline Minimum & -13.271 & -5.554 & -17.462 \\
\hline Std. Dev. & 1.756 & 1.017 & 1.283 \\
\hline Skewness & -0.861 & 0.178 & -1.325 \\
\hline Kurtosis & 7.531 & 5.012 & 26.423 \\
\hline Jarque-Bera & $1,564.685(0.000)^{* * *}$ & $277.941(0.000)^{* * *}$ & $36,997.470(0.00)^{* * *}$ \\
\hline $\mathrm{ADF}$ & $-42.776(0.000) * * *$ & - 36.648(0.000)*** & $-46.037(0.00)^{* * *}$ \\
\hline $\mathrm{PP}$ & $-42.757(0.000)^{* * *}$ & $-36.513(0.000)^{* * *}$ & $-46.207(0.000)^{* * *}$ \\
\hline
\end{tabular}

Notes:

$* * *$ significant at $1 \%$ level;

Critical value for unit root tests are -3.128 at 10\% level, -3.413 for $5 \%$ level, and 3.964 for $1 \%$ level; $H_{0}$ : data series are non - stationary; $H_{1}$ : data series are stationary. 
Table 2

Correlation Among Water Indices

\begin{tabular}{|c|c|c|c|c|c|c|}
\hline & \multicolumn{2}{|c|}{ ASIA } & \multicolumn{2}{|c|}{ EUROPE } & \multicolumn{2}{|c|}{ US } \\
\hline \multicolumn{7}{|c|}{ Period 1 (01/07/1993-10/09/2001) } \\
\hline ASIA & 1.000 & & -0.035 & $(0.106)$ & -0.006 & $(0.773)$ \\
\hline EUROPE & -0.035 & $(0.106)$ & 1.000 & & 0.069 & $(0.001)^{* * *}$ \\
\hline US & -0.006 & $(0.773)$ & 0.069 & $(0.001)^{* * *}$ & 1.000 & 1.000 \\
\hline \multicolumn{7}{|c|}{ Period 2 (17/09/2001-31/10/2007) } \\
\hline ASIA & 1.000 & & 0.089 & $(0.00)^{* * *}$ & 0.018 & $(0.472)$ \\
\hline EUROPE & 0.089 & $(0.00)^{* * *}$ & 1.000 & & 0.168 & $(0.000)^{* * *}$ \\
\hline US & 0.018 & $(0.472)$ & 0.168 & $(0.00)^{* * *}$ & 1.000 & \\
\hline
\end{tabular}

Note: $*$ significant at $5 \%$.

Table 3

Optimal Lag Determination

\begin{tabular}{ccccc}
\hline & \multicolumn{5}{c}{ Lags } \\
\cline { 2 - 5 } Periods & $\mathbf{0}$ & $\mathbf{1}$ & $\mathbf{2}$ & $\mathbf{3}$ \\
\hline Period $1(01 / 07 / 1993-10 / 09 / 2001)$ & -12.048 & $-12.042^{*}$ & -12.055 & -12.067 \\
Period $2(17 / 09 / 2001-31 / 10 / 2007)$ & -10.007 & $-10.004^{*}$ & -10.038 & -10.110 \\
\hline
\end{tabular}

Note: * lowest SIC value.

Table 4

Vector Autoregression Coefficients

\begin{tabular}{|c|c|c|c|c|c|c|}
\hline & \multicolumn{2}{|c|}{ ASIA } & \multicolumn{2}{|c|}{ EUROPE } & \multicolumn{2}{|r|}{ US } \\
\hline \multicolumn{7}{|c|}{ Period 1 (01/07/1993-10/09/2001) } \\
\hline $\mathrm{C}$ & -0.046 & $(0.074)$ & -0.015 & $(0.025)$ & -0.045 & $(0.032)$ \\
\hline $\operatorname{ASIA}(-1)$ & -0.036 & $(0.022)^{* *}$ & -0.007 & $(.007)^{* * *}$ & -0.018 & $(.009)^{* * *}$ \\
\hline EUROPE(-1) & 0.031 & $(0.063)^{*}$ & 0.130 & $(0.022)^{* *}$ & -0.015 & $(0.027)^{* *}$ \\
\hline $\mathrm{US}(-1)$ & -0.016 & $(0.051)^{*}$ & 0.016 & $(0.017)^{* *}$ & -0.032 & $(0.022)^{* *}$ \\
\hline \multicolumn{7}{|c|}{ Period 2 (17/09/2001-31/10/2007) } \\
\hline $\mathrm{C}$ & -0.094 & $(0.044)$ & -0.052 & $(0.025)$ & -0.069 & $(0.030)$ \\
\hline $\operatorname{ASIA}(-1)$ & -0.077 & $(0.025)^{* *}$ & -0.000 & $(0.014)^{* *}$ & -0.015 & $(0.017)^{* *}$ \\
\hline EUROPE(-1) & 0.160 & $(0.044)^{* *}$ & 0.075 & $(0.025)^{* *}$ & 0.014 & $(0.030)^{* *}$ \\
\hline $\mathrm{US}(-1)$ & 0.108 & $(0.034)^{* *}$ & 0.065 & $(0.020)^{* *}$ & -0.082 & $(0.024)^{* *}$ \\
\hline
\end{tabular}

Note: $* * *, * * *$ significant at $10 \%, 5 \%$ and $1 \%$. Standard errors are in parentheses. 
Table 5

Granger Causality Test Results

\begin{tabular}{|c|c|c|c|c|c|c|}
\hline & \multicolumn{2}{|c|}{$\overline{\text { ASIA }}$} & \multicolumn{2}{|c|}{ EUROPE } & \multicolumn{2}{|c|}{ US } \\
\hline \multicolumn{7}{|c|}{ Period 1 (01/07/1993-10/09/2001) } \\
\hline ASIA & - & - & 0.012 & $(0.912)$ & 9.244 & $(0.002)^{* * *}$ \\
\hline EUROPE & 0.565 & $(0.452)$ & - & - & 8.250 & $(0.004)^{* * *}$ \\
\hline US & 2.919 & $(0.088)^{*}$ & 0.001 & $(0.972)$ & - & - \\
\hline \multicolumn{7}{|c|}{ Period 2 (17/09/2001-31/10/2007) } \\
\hline ASIA & - & - & 3.723 & $(0.155)$ & 5.473 & $(0.065)^{*}$ \\
\hline EUROPE & 65.519 & $(0.000) * * *$ & - & - & 0.919 & $(0.632)$ \\
\hline US & 4.625 & $(0.099) *$ & 16.881 & $(0.000)^{* * *}$ & - & - \\
\hline
\end{tabular}

Note: $*, * *, * * *$ significant at $10 \%, 5 \%$ and $1 \%$. Standards errors are in parentheses. 
Table 6

Variance Decomposition

\begin{tabular}{|c|c|c|c|c|}
\hline & ASIA & EUROPE & US & $\begin{array}{c}\text { Total Effect from } \\
\text { Other Markets }\end{array}$ \\
\hline \multicolumn{5}{|c|}{ Period 1 (01/07/1993-10/09/2001) } \\
\hline ASIA & 99.986 & 0.010 & 0.004 & 0.014 \\
\hline EUROPE & 0.196 & 99.765 & 0.039 & 0.235 \\
\hline US & 0.172 & 0.528 & 99.300 & 0.700 \\
\hline $\begin{array}{l}\text { Total effect on } \\
\text { other markets }\end{array}$ & 0.368 & 0.538 & 0.043 & 0.949 \\
\hline \multicolumn{5}{|c|}{ Period 2 (17/09/2001-31/10/2007) } \\
\hline ASIA & 98.351 & 1.114 & 0.535 & 1.649 \\
\hline EUROPE & 0.577 & 98.859 & 0.564 & 1.141 \\
\hline US & 0.199 & 3.249 & 96.552 & 3.448 \\
\hline $\begin{array}{l}\text { Total effect on } \\
\text { other markets }\end{array}$ & 0.776 & 4.363 & 1.099 & 6.238 \\
\hline
\end{tabular}




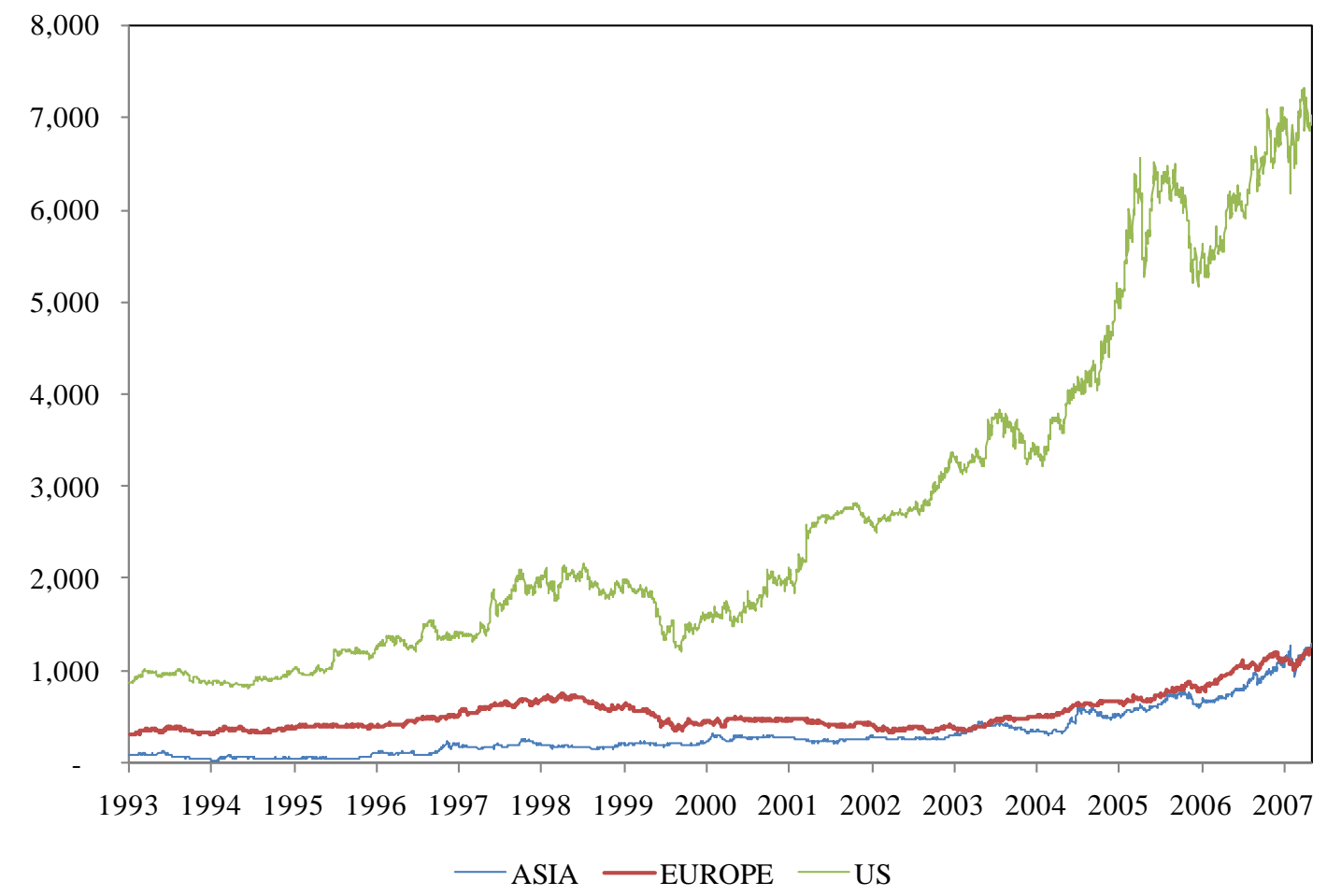

Figure 1. US, European and Asian Water Indices Movement, 1993-2007 

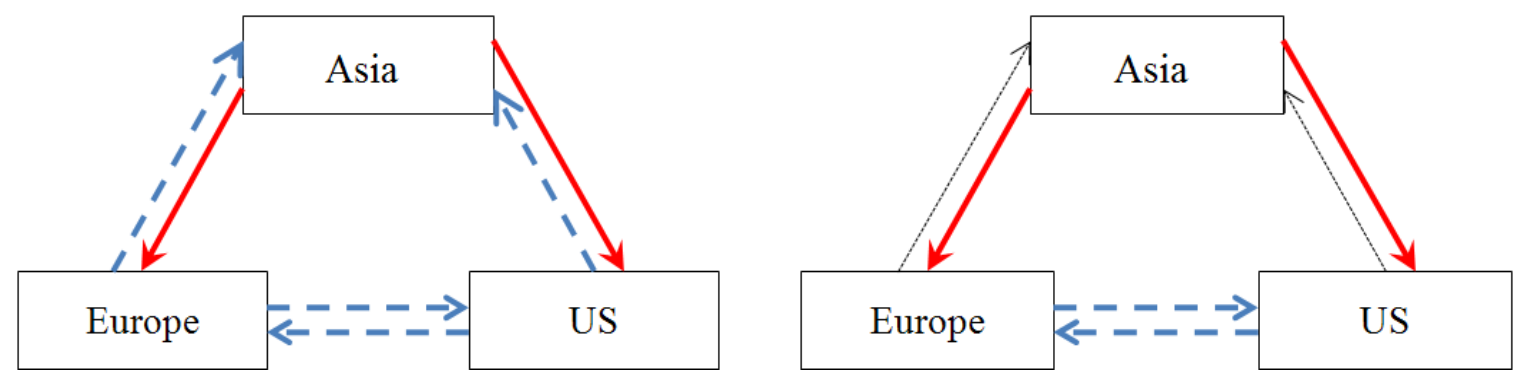

Period 2 (17/09/2001-31/10/2007)

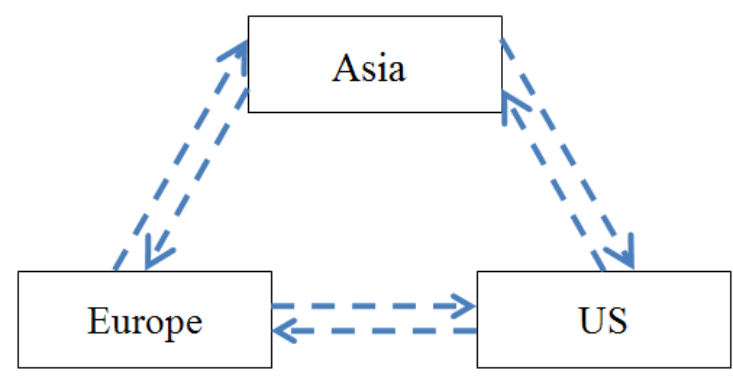

Notes: $\longrightarrow$ indicates null hypothesis is rejected at $10 \%$ level of significance $\cdots . . . \rightarrow$ indicates null hypothesis is rejected at $5 \%$ level of significance $\longrightarrow$ indicates null hypothesis is rejected at $1 \%$ level of significance

Figure 2. Significant Linkages Between Water Sector of World Stock Markets 

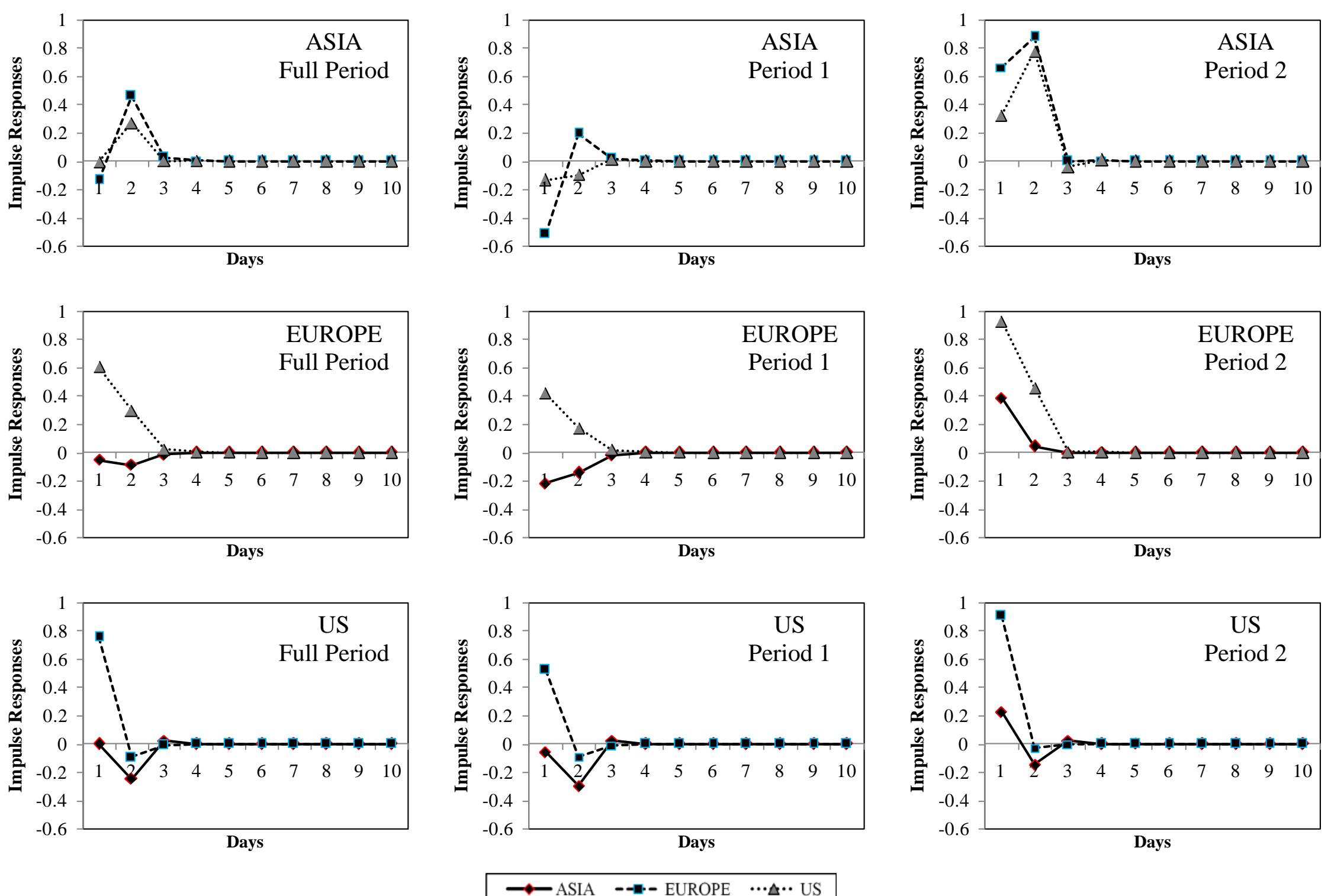

Figure 3. Generalise Impulse Response Between Water Sector of World Markets 
